\title{
A estrutura das representações sociais de mães puérperas acerca da depressão pós-parto
}

\author{
Evelyn Rúbia de Albuquerque Saraiva - Universidade Federal da Paraíba' \\ Maria da Penha de Lima Coutinho - Universidade Federal da Paraíba
}

\begin{abstract}
Resumo
Neste estudo, a depressão pós-parto foi abordada sob a ótica psicossociológica, objetivando apreender e descrever a estrutura central e periférica das representações sociais de mães puérperas. Foram aplicados a técnica de associação livre de palavras, um questionário biodemográfico e a Escala de Edinburg, em 84 participantes de baixa renda e usuárias de um serviço público de saúde. Observou-se uma incidência de $33 \%$ de mães puérperas com sintomatologia de depressão. Para o estímulo indutor "depressão", emergiram, no núcleo central, os elementos de tristeza e aperreio, e na zona periférica evidenciaram-se as representações sociais que se alternaram entre paraíso e padecimento. A condição de ser mãe e ter filho, de acordo com o núcleo central, causa contentamento, gera alegria e prazer e, simultaneamente, está associada ao sofrimento psíquico, à representação social da depressão pós-parto. A constatação desses elementos antagônicos presentes nas representações sociais sinaliza para a necessidade de estudos mais aprofundados.

Palavras-chave: Representações sociais; Depressão pós-parto; Puerpério; Maternidade; Núcleo central.
\end{abstract}

\section{The social representations structure of postnatal mothers about postpartum depression}

\begin{abstract}
In this study, the postpartum depression was dealt with under the psychosociologic view, aiming to learn and describe the central and peripheral structure of postnatal mothers' social representations. To eighty-four participants of low income and users of health public service were applied the free words association, a bio-demografic questionnaire and the Edinburg's Scale. An incidency of $33 \%$ of postnatal mothers with depression symptomatology was noticed. For the inductor stimulus "depression", emerged, on the central core, the elements of sadness and harassment, and on the peripheral zone became evident the social representations that changed between paradise and suffering. The condition of being mother and have child, in accordance with the central core, causes contentment, produces happiness and pleasure and, simultaneously, is associated to the psychic suffering, the social representation of postpartum depression. The verification of these antagonistic elements present on the social representations signalize for the necessity of more deepen studies.

Keywords: Social representations; Postpartum depression; Puerperium; Maternity; Central core.
\end{abstract}

\section{Introdução}

Na sociedade contemporânea, a depressão revelase como um amplo fenômeno de saúde pública e uma doença que, embora muito conhecida há centenas de anos, cada vez mais se destaca como um tema difícil de definir e de explicar. Esta doença ou síndrome, que surge como transtornos biopsicoafetivos, apresenta-se acompanhada de sintomas multivariados, que compreendem aspectos orgânicos, hereditários, sociais, econômicos, religiosos, entre outros, denotando um problema de saúde mental, que preocupa os serviços de saúde, em indivíduos sem distinção de sexo, idade, classe socioeconômica, cultura, raça e país (Coutinho, Gontiés, Araújo \& Sá, 2003).

Nos últimos vinte anos, tem sido reconhecido, em algumas mulheres, que a gravidez, o nascimento de um bebê e o período após o parto podem ocasionar problemas psicoafetivos, em particular, denominados depressão pós-parto. $\mathrm{O}$ nascimento de um bebê tem sido associado a situações de estresse em algumas famílias, diante das mudanças nas rotinas diárias, levando ao registro, na literatura consultada, da ocorrência desse tipo de depressão numa prevalência entre 10\% e 42\% das amostras estudadas. Em estudos brasileiros, destacam-se as prevalências de 37,1\% (Cruz, Simões \& Faisal-Cury, 2005) e 38\% (Da-Silva, Moraes-Santos, Carvalho, Martins \& Texeira, 1998). Nos Estados Unidos da América, os principais escores são de 39\% (Howell, Mora \& Leventhal, 2006) e 42,6\% (Kuo e colaboradores, 2004); no Reino Unido, a prevalência fica entre $12 \%$ e $13 \%$ (Howard,

\footnotetext{
${ }^{1}$ Endereço para correspondência:

Rua Gláucia M. S. Gouveia, 418 - bairro de Manaíra - 58038-640 - João Pessoa-PB

E-mail: evelynsaraiva@hotmail.com
} 
2005); na Índia, mantém-se entre 16\% e 19,8\% (Chandran, Tharyan, Muliyil \& Abraham, 2002); na Turquia, aparece em 27,2\% dos casos (Inandi e colaboradores, 2002); na Austrália, fica entre 10\% e 15\% (Boyce e colaboradores, 2000); nos Emirados Árabes, a prevalência é de 18\% (Abou-Seleh \& Ghubash, 1997); e na Espanha, a prevalência é de 15,7\% (Sierra Manzano, Carro Garcia \& Ladrón, 2002).

Nesse contexto, depressão pós-parto consiste numa expressão do sofrimento e da dor humana e, de acordo com dados epidemiológicos, acomete um expressivo número de mulheres em todo o mundo. Esta doença mostra-se acompanhada de manifestações biopsicossociais associadas à ocorrência de eventos estressantes. Também denominado de depressão puerperal, maternal ou pós-natal, esse transtorno depressivo possui sintomas multivariados e é investigado como um tipo de depressão reativa. Por se tratar de uma reação a estímulos externos ao indivíduo, esse tipo de transtorno psicoafetivo enquadra-se como uma forma não patológica de sofrimento psíquico.

A depressão comumente associada ao nascimento de um bebê refere-se a um conjunto de sintomas que incluem irritabilidade, choro freqüente, sentimentos de desamparo e desesperança. Além desses elementos, há a presença da falta de energia e motivação, desinteresse sexual, transtornos alimentares e do sono, a sensação de ser incapaz de lidar com novas situações, bem como queixas psicossomáticas (Schwengber \& Piccinini, 2003). Apesar da alta incidência e também das múltiplas características deste transtorno depressivo, o seu reconhecimento e confirmação, muitas vezes, contrariam a sabedoria popular. O senso comum a respeito das expressões afetivas vinculadas ao período da maternidade aponta para uma crença de que essa vivência proporciona sentimentos agradáveis e prazerosos para todas as mulheres, longe, portanto, de vir atrelada ao sofrimento e à dor humana.

Nesta pesquisa, a fim de caracterizar e situar o período correpondente à maternidade, adotou-se o conceito de puerpério, como o período cronologicamente variável, de âmbito impreciso, durante o qual se desenrolam todas as manifestações involutivas ou de recuperação da genitália materna havidas após o parto. Essa etapa compreende os seguintes períodos, que se sucedem logo após o parto: pós-parto imediato, do primeiro ao décimo dia; pós-parto tardio, do décimo ao $45^{\circ}$ dia; e o pós-parto remoto, além do $45^{\circ}$ dia (Resende \& Montenegro, 1999). Na presente investigação, toma-se, como referencial do puerpério, aquele formado pelas fases tardias e remotas.

Além do período de involuções da genitália, a fase do puerpério também está relacionada à amamentação e ao período de licença do trabalho. Estas etapas se assemelham entre si, pois proporcionam interações intensivas entre mães e bebês, ocasionadas pelo aleitamento materno exclusivo, bem como pela dedicação ao bebês em tempo integral.

Este estudo sobre a depressão puerperal remete, ainda, à influência deste adoecimento sobre a saúde da mulher, com repercussões na interação social da mãe com o seu bebê e com toda a sua família (Frizzo \& Piccinini, 2005). Esta situação vem demandando a necessidade de abordá-la no bojo de programas de saúde pública, voltados para a função reprodutiva da população feminina. Compreendidos num contexto socioeconômico e cultural, tais programas devem destacar o papel social da mulher diante dos desafios contemporâneos que estão a exigir novas adaptações inter e intrapessoais e de mudança de identidade feminina (Moreira \& Lopes, 2006).

Nessa perspectiva, este estudo pretende abordar o tema depressão puerperal sob a ótica da psicologia social, buscando apreender e descrever a estrutura central e periférica das representações sociais de mães puérperas, acerca da depressão pós-parto. Para instrumentalizar esta investigação, utiliza-se uma abordagem psicossocial, ancorada na Teoria das Representações Sociais (Moscovici, 1978, 2003) e na Teoria do Núcleo Central (Abric, 2003).

As representações sociais são conjuntos simbólicos/práticos/dinâmicos cujo status é o de uma produção e não de uma reprodução. Significa dizer que constituem não uma simples reação a estímulos exteriores, mas sim a seleção e utilização, a partir de repertório circulante na sociedade, de informações destinadas à interpretação e à elaboração do real. Assim, representar um objeto, pessoa ou coisa não consiste apenas em desdobrá-los, repeti-los ou reproduzi-los, mas em reconstruí-los, retocá-los e modificá-los (Moscovici, 2003).

Enquanto uma modalidade de conhecimento particular, a representação social tem por função a elaboração de comportamentos e a comunicação entre os indivíduos, considerando a indissociabilidade entre a experiência subjetiva e a inserção social dos sujeitos (Moscovici, 1978). Por conseguinte, as representações sociais das puérperas sobre seus transtornos psicoafetivos podem ser compreendidas como uma interpretação coletiva da realidade vivida e falada por aquele grupo social, direcionando comportamentos e comunicações.

Ao abordar a depressão pós-parto no âmbito das representações sociais, este estudo pretende investigar como o fato novo na vida das mulheres puérperas, que ocorre com o nascimento de um bebê e com a vivência da maternidade, se transforma em algo familiar e particular. Em conformidade com a Teoria das Representações Sociais, a integração dessa novidade nas vivências individuais e sociais das mulheres puérperas pode ser analisada por meio dos processos sociocognitivos da

Psico-USF, v. 12, n. 2, p. 319-326, jul./ dez. 2007 
ancoragem e da objetivação. Estudar as representações sociais das mães puérperas acerca da depressão pós-parto significa compreender os processos de classificação e nomeação que permitem retirar a novidade - a experiência com a maternidade - do anonimato e ancorá-la numa rede de significação, a partir do consenso do grupo de mulheres que convivem num mesmo serviço público de saúde. Neste ambiente social, são veiculadas as crenças, opiniões, sentimentos acerca da experiência de ser mãe.

A objetivação é um processo interligado à ancoragem que contribui para o surgimento de uma representação social ante um novo objeto, por meio da identificação do elemento figurativo e da naturalização de uma entidade abstrata, que foi ancorada pela classificaşão e pela nomeaşão (Moscovici, 2003). O elemento figurativo é identificado a partir das expressões mais conhecidas e usadas pelos indivíduos de um grupo social ou de pertença. $\mathrm{O}$ grupo social procura selecionar a expressão que mais se aproxima da capacidade figurativa, conservando as crenças passadas do grupo, assim como os conjuntos de imagens construídas socialmente. $\mathrm{Na}$ naturalização, o grupo social, ao identificar os elementos do núcleo figurativo de uma representação social, integraos aos elementos da realidade do senso comum (Moscovici, 2003).

Para a apreensão do elemento figurativo da Teoria das Representações Sociais de Moscovici, utilizarse-á a Teoria do Núcleo Central. Trata-se de uma abordagem específica no campo das representações sociais, considerada como uma proposição teóricometodológica complementar ao estudo de Moscovici, de modo a torná-lo mais heurístico tanto na prática social quanto para a pesquisa. A Teoria do Núcleo Central propõe-se a identificar e analisar os processos que determinam as representações sociais enquanto conjuntos sociocognitivos organizados e estruturados em dois subsistemas: um sistema central e um sistema periférico (Abric, 1998, 2003).

O conhecimento do conteúdo de uma representação social não é suficiente para defini-la, sendo necessário identificar os elementos centrais - o núcleo central. Esse núcleo central possibilita à representação sua significação, que termina os laços que unem entre si os elementos do conteúdo e que regem a sua evolução e a sua transformação. O núcleo central é um elemento unificador e estabilizador das representações sociais (Abric, 2003). O outro subsistema estrutural, o sistema periférico, organizado em torno do núcleo central, funciona na periferia da representação social, servindo de "pára-choque entre uma realidade que a questiona e um núcleo central que não deve mudar facilmente" (Flament, 2001, p. 178). Essa afirmação assinala que, para ser protegido o núcleo central e para ser assegurada a estabilidade de uma Psico-USF, v. 12, n. 2, p. 319-326, jul./de₹: 2007 representação social, na sua periferia comportam as verbalizações mais subjetivas e menos freqüentes proferidas pelo grupo de pertença acerca do objeto representacional e, por esse motivo, absorvidas pelos esquemas periféricos. Deste modo, o sistema periférico serve de dispositivo para amortecer o confronto entre a realidade subjetiva e os elementos consensuais, constitutivos do núcleo central de uma representação social.

Falar da representação social acerca da depressão pós-parto consiste, portanto, num conjunto sociocognitivo resultante da interpretação do universo simbólico e social, que dirige as relações das mães puérperas com o seu meio físico e social, determinando seus comportamentos e suas práticas e guiando, portanto, suas ações sociais.

\section{Método}

\section{Aspectos éticos e participantes}

Este estudo foi aprovado pelo Comitê de Ética do Centro de Ciências da Saúde da Universidade Federal da Paraíba, conforme a Res. CNS/MS, n 196/96 (Brasil, 1996). Trata-se de um estudo descritivo, com a amostra constituída de 84 mães usuárias do serviço público de saúde onde a pesquisa foi realizada, que se encontravam acompanhadas de seus bebês na sala de espera dos setores de pediatria e de vacinas. As mães não se encontravam presentes ao serviço público de saúde em busca de atendimento para si próprias, e sim para consultas e vacinas dos seus bebês. As participantes atenderam aos seguintes requisitos: a) tinham idade igual ou superior a 18 anos; b) seus partos ocorreram entre quinze e noventa dias antes da aplicação dos instrumentos da pesquisa; c) ofereciam ao seu bebê o leite materno como único alimento; e d) cuidavam de seu filho em tempo integral.

As participantes possuíam idades que variavam entre 18 e 38 anos ( $\mathrm{X}=27$ anos, $\mathrm{DP}=3,07)$; o período de puerpério observado foi entre 15 a 90 dias $(X=42$ dias, $\mathrm{DP}=4,46)$ e a grande maioria, ou seja, $84 \%$, teve parto vaginal ou normal. Quanto ao número de filhos, $58 \%$ das participantes tinham apenas 1 filho e as demais possuíam entre 2 e 4 filhos. A maioria das mães (55\%) não era casada no civil, residindo com seus companheiros, enquanto $8,8 \%$ eram solteiras e $35 \%$ eram casadas.

A maioria das mães estudadas (47\%) tinha o ensino fundamental incompleto. $22 \%$ não concluíram o ensino médio, 4\% concluíram o ensino superior e as demais concluíram o ensino fundamental e o médio. Entre as participantes, $51 \%$ professavam a religião católica, $21 \%$ a evangélica e as demais não tinham religião. Quanto à renda familiar por pessoa, a maioria, $64 \%$, situou-se na 
faixa abaixo de $\mathrm{R} \$ 180,00$, seguida da faixa entre $\mathrm{R} \$ 181,00$ e $\mathrm{R} \$ 250,00$, com $25 \%$ da amostra, enquanto $11 \%$ possuíam renda familiar por pessoa de até $\mathrm{R} \$ 500,00$. O registro de ocupação apresentou as seguintes percentagens: $64 \%$ não tinham ocupação fora de casa, $10 \%$ eram empregadas domésticas sem vínculo empregatício, $6 \%$ eram estudantes e as demais mães situavam-se entre as autônomas e as assalariadas.

\section{Local da pesquisa e instrumentos}

A pesquisa foi desenvolvida no Ambulatório Materno-Infantil do Instituto Cândida Vargas. Trata-se de serviço público municipal de saúde localizado em João Pessoa, na Paraíba, que conta com uma equipe multidisciplinar, incluindo profissionais da Psicologia. Foram utilizadas a Técnica de Associação Livre de Palavras (TALP), o Questionário Biodemográfico e a Escala de Edinburgh (Edinburgh Postpartum Depression Scale). Essa escala é um instrumento de auto-registro, validado no Brasil para rastreamento da depressão pós-parto (Santos, Martins \& Pasquali, 1999) e formado por dez enunciados, referindo-se a sintomas de humor deprimido, distúrbio do sono, perda de prazer, idéias de morte e suicídio, diminuição do desempenho e culpa. Submetida à análise fatorial, a escala revelou duas dimensões constitutivas, depressão e ansiedade cognitiva, com seus itens apresentando uma consistência interna de 0,80, medida pelo coeficiente alfa de Cronbach e um ponto de corte de $11 / 1$, com um valor preditivo de $78 \%$.

\section{Procedimentos}

As respostas coletadas pela Escala de Edinburgh foram pontuadas de 0 a 3 pontos, sendo consideradas portadoras de depressão pós-parto as participantes que obtiveram 11 pontos ou mais. Os dados do questionário foram processados pelo pacote estatístico SPSS (versão 13.0). Para o TALP, foram aplicados os estímulos indutores: "depressão", "ser mãe" e "ter filho(a)", seguindo uma ordem aleatória da apresentação, e as respostas das participantes foram processadas por meio do programa computacional EVOC (Vergès, 2002). Esse programa permite a identificação dos temas que emergem do núcleo central e do sistema periférico das representações sociais, a partir das respostas a cada um dos estímulos indutores apresentados (Abric, 1998; Sá, 1998; 2001). Com base nessas características, o EVOC elaborou uma análise lexicográfica, que levou em conta a freqüência dos termos evocados e a ordem de aparecimento das respostas registradas, demonstrando graficamente as palavras pertencentes ao núcleo central e ao sistema periférico das representações sociais das participantes.

\section{Resultados e discussão}

Entre as mães investigadas, 33\% apresentaram pontuações iguais ou acima de 11 pontos na Escala de Edinburgh, caracterizando a sintomatologia de depressão pós-parto. Essa alta prevalência encontra-se acima dos percentuais alcançados pelos estudos de Howard (2005), Chandran e colaboradores (2002), Inandi e colaboradores (2002), Boyce e colaboradores (2000), Abou-Seleh e Ghubash (1997) e Sierra Manzano e colaboradores (2002). Com base nos dados obtidos no Teste de Associação Livre de Palavras e no seu processamento pelo EVOC, foi possível elaborar as Figuras 1, 2 e 3, contendo as palavras evocadas, a sua freqüência e a ordem de aparecimento das respostas.

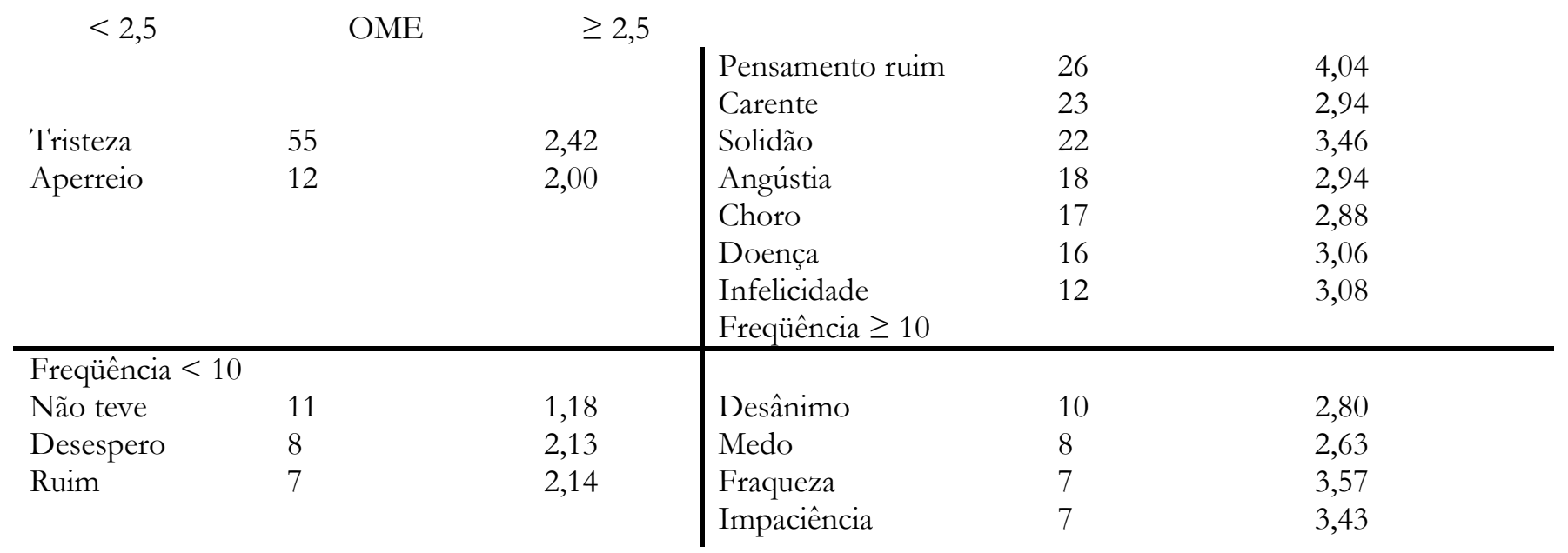

Figura 1 - Quadrante de distribuição das evocações livres das mães puérperas no Teste de Associação Livre de Palavras para o estímulo indutor "depressão" $(\mathrm{N}=84)$ 
De acordo com a Figura 1, para o estímulo indutor "depressão", cada palavra evocada foi registrada com sua respectiva freqüência acima ou abaixo de $10 \mathrm{e}$ ordem de aparecimento da resposta acima ou abaixo de 2,5. As respostas das participantes indicaram, no quadrante superior esquerdo, no seu núcleo central, as evocações "tristeza e aperreio". O sentimento de tristeza, enquanto elemento unificador e estabilizador das representações sociais acerca da depressão pós-parto, expressa o sofrimento psíquico que acompanha a vivência subjetiva e social da concepção, gestação, parto e puerpério das mães estudadas, que se relaciona às necessidades de novas adaptações e reajustamentos intrapsíquicos, interpessoais e de mudança de identidade feminina (Moreira \& Lopes, 2006). Esta representação social acerca da depressão está ancorada no conhecimento erudito manifesto pela nosologia psiquiátrica ou pela psicologia clínica, cujos estudos remetem às descrições internacionais da depressão, enquanto transtorno psicoafetivo ou do humor, a exemplo do que acontece com a CID-10 da Organização Mundial da Saúde (WHO, 2007), combinada com o DSMIV, da Associação Psiquiátrica Americana (APA, 1994).

O outro elemento que emerge no núcleo central da representação social da depressão, ao lado da tristeza das puérperas, é o "aperreio", um termo muito utilizado na Região do Nordeste do Brasil. Segundo Ferreira (1995), este termo significa, basicamente, um estado de sujeição, opressão, apoquentação, apuro e dificuldade. Nesse sentido, pode ser considerado um conceito sintetizador de um conjunto de outros elementos ancorados nos registros psicoafetivos do sofrimento psíquico.

Os sistemas periféricos próximo e distante, localizados, respectivamente, nos quadrantes superior direito/inferior esquerdo e no quadrante inferior direito da Figura 1, parecem desdobrar o conceito unificador de "aperreio" nos elementos denotativos de "pensamento ruim", que envolve opressão, ideação suicida e desejo de doar o filho indesejado. Ficar aperreada, enquanto senso comum das mães puérperas, revela o conjunto de sintomas presentes no sentimento de abandono ("solidão e carência"), no "choro", revelador de "angústia, desespero, impaciência e infelicidade", e nas queixas psicossomáticas, do tipo "doença, fraqueza e desânimo" (Schwengber \& Piccinini, 2003).

Essa constatação também vem reforçar a convergência do senso comum com os estudos eruditos, as pesquisas científicas, que manifestam conceituações da vivência do adoecer psíquico, que ultrapassam a esfera físico-orgânica. Ressalte-se, ainda, no sistema periférico, as expressões das mães que "não tiveram" depressão, diferentemente da maioria da amostra estudada. Suas evocações de "desespero" e de experiência "ruim" denotam um sentimento de alteridade, uma vez que, apesar de informarem que não vivenciam a depressão, as mães se identificam, na relação com o seu grupo de pertença, com as mulheres puérperas em depressão pósparto, representando socialmente este sofrimento psíquico.

$$
<2,2
$$

Tudo

Bom

Maravilhoso
OME

$$
19
$$

11

$$
\geq 2,2
$$

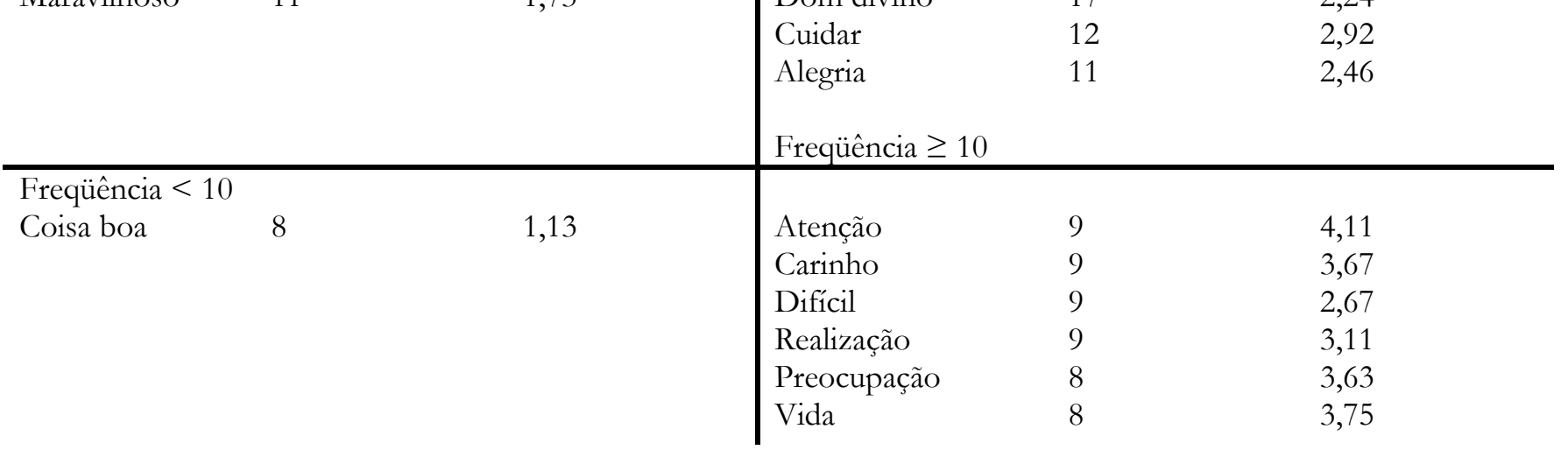

Figura 2 - Quadrante de distribuição das evocações livres das mães puérperas no Teste de Associação Livre de Palavras para o estímulo indutor "ser mãe" $(\mathrm{N}=84)$ 
De acordo com a Figura 2, para o estímulo indutor "ser mãe", cada palavra evocada foi registrada com sua respectiva freqüência acima ou abaixo de $10 \mathrm{e}$ com a ordem de aparecimento da resposta, acima ou abaixo de 2,2. As respostas das puérperas apresentaram, no núcleo central, uma dimensão valorativa vinculada às expressões "é ‘bom' ser mãe", "ser mãe é ‘tudo' e é uma experiência 'maravilhosa". Para este mesmo estímulo "ser mãe" emergiram, enquanto elementos periféricos, expressões tanto positivas, como "carinho e realização", quanto denotativas de aspectos negativos, como "preocupação" e uma experiência "difícil", que exige "atenção" da nova mãe. As representações sociais acerca de ser mãe parecem apontar para sentimentos ambivalentes, que oscilam entre o paraíso e os padecimentos desta nova experiência.
$<2,6$

OME

\begin{tabular}{lll}
\multicolumn{2}{c}{$<2,6$} & OME \\
& & \\
Alegria & 22 & 2,00 \\
Prazer & 11 & 2,46 \\
Responsabilidade & 10 & \\
& & \\
& & \\
& & \\
& & \\
Freqüência $<10$ & & \\
& & \\
Desejada & 9 & 1,34 \\
Muito bom & 9 & 1,88 \\
Dom divino & 8 & 2,57 \\
Meu/minha & 7 &
\end{tabular}

$\geq 2,6$

\begin{tabular}{|lll} 
Felicidade & 43 & 2,74 \\
Amor & 20 & 2,75 \\
Futuro & 18 & 2,94 \\
Carinho & 16 & 3,06 \\
Dedicação & 16 & 4,00 \\
Vida & 16 & 4,00 \\
Tudo & 13 & 2,92 \\
Bom & 12 & 3,25 \\
Cuidado & 11 & 3,36 \\
Freqüência $\geq 10$ & &
\end{tabular}

,74

75

,94

4,00

4,00

2,92

3,25

,36
Freqüência $\geq 10$

$\begin{array}{lll}\text { Realização } & 9 & 3,67 \\ \text { Saúde } & 9 & 4,67 \\ \text { Amadurecimento } & 7 & 3,86\end{array}$

Figura 3 - Quadrante de distribuição das evocações livres das mães puérperas no Teste de Associação Livre de Palavras para o estímulo indutor "ter filho(a)" (N=84)

De acordo com a Figura 3, para o estímulo indutor "ter filho(a)", cada palavra evocada foi registrada com sua respectiva freqüência acima ou abaixo de 10 e a ordem de aparecimento da resposta, acima ou abaixo de 2,6. O núcleo central, encontrado para este estímulo, concentra-se nas expressões de "alegria e prazer", embora as verbalizações venham objetivadas com o peso da "responsabilidade". No sistema periférico, destacam-se as manifestações que promovem "amadurecimento" e "realização pessoal", realçando o desejo futuro de que o filho cresça com "saúde".

As evocações constantes do elemento periférico dos dois estímulos "ser mãe" e "ter filho(a)" parecem demonstrar a estrutura representacional semelhante e interligada. No entanto, esse paralelo está posto no sentido inverso. Para o "ser mãe" surgem as evocações dirigidas ao filho (dar "atenção e carinho", e proporcionar a "vida"). Por sua vez, por contraste, para o "ter filho(a)", o sistema periférico evidencia as conseqüências na vida da mãe: "realização e amadurecimento".
Analisando as evocações para o estímulo "ser mãe", pode-se observar a função de pára-choque, destacada por Flament (2001) e revelada pela presença de manifestações positivas e negativas no último quadrante. $\mathrm{O}$ antagonismo em relação ao lado positivo de ser mãe (é bom), parece ficar demonstrado por expressões como "preocupação" e uma experiência "difícil", que exige "atenção" da nova mãe. No caso da representação social do "ter filho(a)", a evocação ter "responsabilidade" emerge no núcleo central amenizando as expressões positivas de "alegria e de prazer" de ter filho. Portanto, os elementos periféricos revelados para os estímulos "ser mãe" e "ter filho(a)" suportam as múltiplas discordâncias, com a alternância da maternidade enquanto paraíso e padecimento, porque a condição de ser mãe (ou de ter filho) causa contentamento e gera "alegria e prazer", ancorada em manifestações psicoafetivas vinculadas ao período puerperal. 


\section{Considerações finais}

Apreender e descrever as representações sociais da depressão pós-parto, tomando como referência um conhecimento elaborado e compartilhado socialmente por mães puérperas usuárias de um serviço público de saúde, permitiu identificar a estrutura desse fenômeno social através do estudo tanto do seu núcleo central como do seu sistema periférico. Por sua vez, a análise do contexto relacionado à maternidade, a partir dos estímulos "ser mãe" e "ter filho(a)", possibilitou a compreensão das representações sociais da experiência materna enquanto uma vivência exclusivamente feminina. Essas representações se deram a partir de suas elaborações cognitivas e afetivas, percepções e experiências de vida compartilhadas por crenças, atitudes, valores e informações, objetivadas pelos elementos "alegria, prazer" e experiência "maravilhosa" e ancoradas pelos sistemas psicorgânicos do puerpério e o contexto social no qual as participantes encontram-se inseridas.

As representações sociais elaboradas pelas participantes desta investigação denotaram uma aproximação com a concepção de depressão descrita tradicionalmente pela nosologia psiquiátrica, revelando um agrupamento de elementos sintomatológicos em torno do núcleo central formado pela "tristeza" e pelo "aperreio". Esses elementos encontram-se acompanhados de evocações do sistema periférico que refletem situações preocupantes, na medida em que estão sendo representadas por participantes cujas experiências na díade mãe-filho encontram-se ainda na fase de simbiose, isto é, relacionada à situação de entendimento íntimo entre duas pessoas, mãe-filho.

Essa preocupante realidade constatada, aliada à alta prevalência de depressão pós-parto registrada na amostra estudada, reforça a necessidade de uma urgente atenção e intervenção dos profissionais da saúde na direção de uma maior visibilidade para as dificuldades maternas que se escondem por trás da busca do atendimento exclusivamente para seus bebês. A visibilidade do sofrimento após o parto poderá prevenir graves problemas pessoais e familiares decorrentes desse tipo de transtorno biopsicoafetivo.

O resultado deste estudo também sinaliza para suas limitações, voltadas para, pelo menos, duas necessidades de complementação: a utilização de uma abordagem multimétodo e de análises comparativas entre as participantes com e sem sintomatologia de depressão pós-parto. Essa complementaridade de informações é imprescindível para uma melhor apreensão e descrição das representações sociais acerca da depressão pós-parto enquanto um fenômeno psicossocial.

\section{Referências}

Abou-Saleh, M. T. \& Ghubash, R. (1997). The prevalence of early postpartum psychiatric morbidity in Dubai: a transcultural perspective. Acta Psychiatr Scand, 95(5), 428432.

Abric, J. C. (1998). A abordagem estrutural das representações sociais. Em A. S. Moreira \& D. C. Oliveira. (Orgs.). Estudos interdisciplinares de representacōes sociais (pp. 27-38). Goiânia: AB.

Abric, J. C. (2003). L'analyse structurale des représentations sociales. Em S. Moscovici \& F. Buschini. Les méthodes des sciences bumaines (pp. 375-392). Paris: PUF.

APA - American Psychiatric Association (1994). Diagnostic and Statistical Manual of Mental Disorders (4th ed.). Washington, DC: American Psychiatric Association.

Boyce, P. M., Johnstone, S. J., Hickey, A. R., Morris-Yates, A. D., Harris, M. G. \& Strachan, T. (2000). Functioning and well-being at 24 weeks postpartum of women with postnatal depression. Archives of Women's Mental Health, 3(3), 91-97.

Brasil (1996). Ministério da Saúde. Conselho Nacional de Saúde. Resolução no 196, de 10/10/1996. Obtido em 24 de novembro de 2005 do World Wide Web: http://conselho.saude.gov.br/docs/Resolucoes/Reso19 6.doc.

Chandran, M., Tharyan, P., Muliyil, J. \& Abraham, S. (2002). Post-partum depression in a cohort of women from a rural area of Tamil Nadu, India: Incidence and risk factors. The British Journal of Psycbiatry, 181(6), 499504.

Coutinho, M. P. L., Gontiés, B., Araújo, L. F. de \& Sá, R. C. da N. (2003). Depressão, um sofrimento sem fronteira: representações sociais entre crianças e idosos. Psico-USF, 8(2), 183-192.

Cruz, E. B. da S., Simões, G. L. \& Faisal-Cury, A. (2005). Rastreamento da depressão pós-parto em mulheres atendidas pelo Programa de Saúde da Famillia. Rev. Bras. Ginecol. Obstet., 27(4), 181-188.

Da-Silva, V. A., Moraes-Santos, A. R., Carvalho, M .S., Martins, M. L. P. \& Teixeira, N. A. (1998). Prenatal and postnatal depression among low income Brazilian women. Braz. J. Med. Biol. Res., 31(6), 799-804.

Ferreira, A. B. de H. (1995). Dicionário Aurélio básico da lingua portuguesa. Rio de Janeiro: Nova Fronteira.

Flament, C. (2001). Estrutura e dinâmica das representações sociais. Em D. Jodelet (Org.). As representaçoes sociais (pp. 173-186). Rio de Janeiro: UERJ. 
Frizzo, G. B. \& Piccinini, C. A. (2005). Interação mãe-bebê em contexto de depressão materna: aspectos teóricos e empíricos. Psicologia em Estudo, Maringá, 10(1), 47-55.

Howard, L. (2005). Posnatal depression. Obtido em 3 de maio de 2006 do World Wide Web: http:// www.clinicalevidence.com/ceweb/conditionpdf/140 7.pdf.

Howell, E. A., Mora, P. M. \& Leventhal, H. (2006). Correlates of early postpartum depressive symptoms. Maternal and Child Health Journal, 10(2), 149-157.

Inandi T., Elci O. C., Ozturk A., Egri M., Polat A. \& Sahin, T. K. (2002). Risk factors for depression in postnatal first year, in eastern Turkey. Int. J. Epidemiol., 31(6), 12011207.

Kuo, W-H, Wilson, T. E., Holman, S., Fuentes-Afflich, E., O’Sullivan, M. J. \& Minkoff, H. (2004). Depressive simpthoms in the immediate postpartum period among Hispanic women in three U. S. Cities. Journal of Immigrant Health, 6(4), 145-153.

Moreira, R. \& Lopes, R. L. (2006). Sexualidade e gravidez: aspectos da vida da mulher - revisão da literatura. Online Brazilian Journal of Nursing [On-line], 5(1). Obtido em 23 de setembro de 2006 do World Wide Web: http:/ / www.uff.br/objnursing/viewarticle.php?id=250.

Moscovici, S. (1978). A representação social da psicanálise. Rio de Janeiro: Zahar.

Moscovici, S. (2003). Representações sociais: investigações em psicologia social ( $2^{\mathrm{a}}$ ed.). Petrópolis: Vozes,

Resende, J. de \& Montenegro, C. A. B. (1999). Obstetrícia fundamental ( $8^{\mathrm{a}}$ ed.). Rio de Janeiro: Guanabara/Koogan.
Sá, C. P. (1998). A construção do objeto de pesquisa em representações sociais. Rio de Janeiro: UERJ.

Sá, C. P. (2001). Núcleo central das representações sociais (2 $2^{\mathrm{a}} \mathrm{ed}$.). Rio de Janeiro: Vozes.

Santos, M. F. S. dos, Martins, F. C. \& Pasquali, L. (1999). Escala de auto-avaliação de depressão pós-parto: estudo no Brasil. Rev. Psiq. Clín., 26(2) edição especial, 90-95.

Schwengber, D. D. de S. \& Piccinini, C. A. (2003). O impacto da depressão pós-parto para a interação mãebebê. Estud. psicol. (Natal), 8(3), 403-411.

Sierra Manzano, J. M., Carro García, T \& Ladrón, M. E. (2002). Variables associated with the risk of postpartum depression (Edinburgh Postnatal Depression Scale). Aten Primaria, 30(2), 103-11.

Vergès, P. (2002). Ensemble de programmes permettant l'analyse des evocations - EVOC2000, Version 5 Avril 2002. Aix em Provence, France.

WHO - World Health Organization (2007). Intenational statistical classification of disears and related health problems. $10^{\text {th }}$ Revision [On-line]. Obtido em 9 de junho de 2007 do World Wide Web: http://www.who.int/classification/ apps/icd/icd10online.

Sobre as autoras:

Evelyn Rúbia de Albuquerque Saraiva é docente da Universidade Federal da Paraíba - UFPB, psicóloga, mestranda do Programa de Pós-Graduação em Psicologia Social da UFPB e integrante do Núcleo de Pesquisa Aspectos Psicossociais de Prevenção e Saúde Coletiva da Pós-Graduação em Psicologia Social da UFPB.

Maria da Penha de Lima Coutinho é pós-doutora pela Universidade Aberta de Lisboa, Portugal, doutora em Psicologia Clínica pela Universidade de São Paulo, psicóloga formada na Universidade Federal da Paraíba - UFPB, docente da UFPB e coordenadora do Mestrado em Psicologia Social da UFPB e do Núcleo de Pesquisa Aspectos Psicossociais de Prevenção e Saúde Coletiva da Pós-Graduação em Psicologia Social da UFPB. 